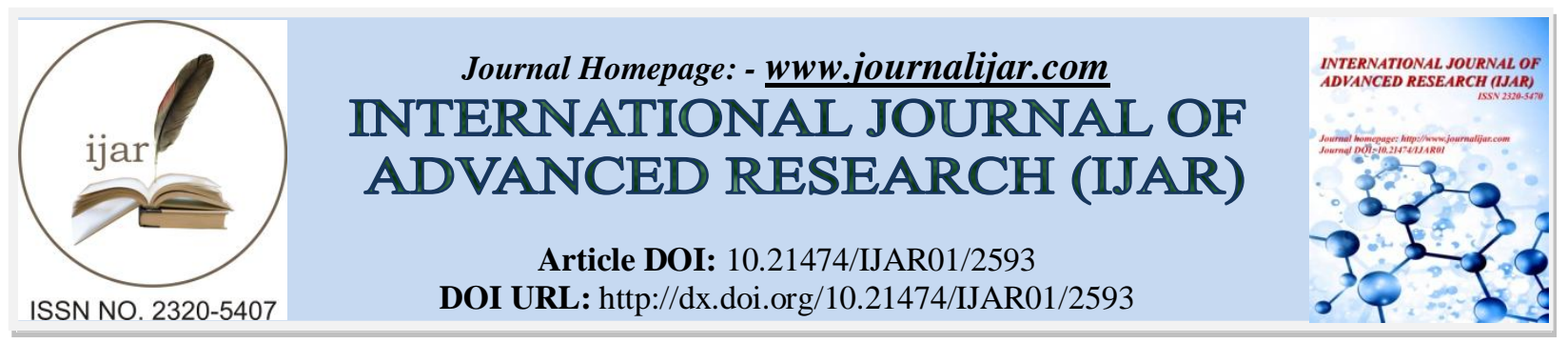

RESEARCH ARTICLE

\title{
AN OVERVIEW ON THE FUNDAMENTALS OF PECTIN.
}

Prakash Narasimman ${ }^{1}$ and Priya Sethuraman ${ }^{2}$.

1. Prakash Narasimman (PG Scholar, Kongu Engineering College, Perundurai, Erode, Tamil Nadu, India.

2. Priya Sethuraman (PG Scholar: College of Food and Dairy Technology, Koduvalli, Chennai-52, Tamil Nadu, India.

\section{Manuscript Info} .........................

\section{Manuscript History}

Received: 27 October 2016

Final Accepted: 25 November 2016

Published: December 2016

Key words:-

pectin, food, industry, pharmaceutical, esterification, Gel formation

\section{Abstract}

Pectin is an important polysaccharide with applications in foods, Pharmaceuticals, and a number of other industries. Its importance in the food sector lies in its ability to form gel in the presence of $\mathrm{Ca}^{2+}$ ions or a solute at low $\mathrm{pH}$. In food industry, pectin is used in jams, jellies, frozen foods, and more recently in low- calorie foods as a fat and/or sugar replacer. Pilgim et al. (1991). It is used to reduced blood cholesterol and gastrointestinal disorders. Pectin is also used in various applications such as edible films, paper substitute, foams and plasticizers, etc. Pectins are heat sensitive, so temperature is monitored strictly during extraction in order to obtain the highest quality product. Pectins are most widely present in apple pomace and orange peel which are commercially extracted. It is used in low-sugar and low-fat applications. It has been used as a carrier for drug delivery to the gastrointestinal tract in the form of matrix tablets, gel beads, film-coated dose form. From a culinary perspective, pectin is widely used in enhancing the flavour properties in food. This review will discuss the importance, chemisty, gel formation mechanism and fundamental of pectin used in the food industry.

Copy Right, IJAR, 2016,. All rights reserved.

\section{Pectin- a plant source:-}

Pectin is the key component in fruit responsible for the formation of a gel after heating and addition of sugars. Pectin is generally defined as water-soluble pectinic acids with varying methyl ester contents which are capable of forming gels in addition with sugar and acid when exposed to the correct conditions. Due to its outstanding gelling ability, pectin is a common food ingredient. Pectin is made up of $\alpha-(1,4)$ linked D-galacturonic acid units linked in a linear fashion. Pectin molecules also contain rhamnogalacturonan, a neutral sugar, which is responsible for splitting and causing kinks in the galacturonic acid chain (Thakur et al., 1997). Pectic substances are "complex colloidal carbohydrate derivatives that occur in, plants and contain a large proportion of anhydro-galacturonic acid units." Protopectin is a substance found in plant cell walls from which pectin is created (Monhen 2008). Unlike pectin, protopectin is insoluble in water due to the fact that all of its carboxyl groups are esterified with methanol. Enzyme hydrolysis of protopectin within the plant will yield pectinic acids leading to the softening and ripening of fruits during which protopectin is converted to water soluble pectin (Yamaki et al., 1979). Pectinic acids are polygalacturnonic acid units that contain more than a minimal number of methoxyl groups. Pectinic acids also contains neutral sugars such as arabinose, galactose, rhamnose, and xylose. (Yapo et al 2007). It is a natural prophylactic substance is used as detoxification agent. In mining industries the workers face many serious problems, 
due to the toxic cations like mercury, cadmium, lead, arsenic. These cations enter the gastrointestinal tract and respiratory track and causes serious problems. Pectin is used in the detoxification of these cations and thereby cures many diseases. Pectin is also used to protect against radioactivity. Pectin, shortens the coagulating time of blood. The galacturonan molecule present in the pectin initiates the coagulation at faster rate. Cancer too is prevented by pectin molecules in the blood stream. Pectin blocks angiogenesis in cancer cells which results in death of the cancer cell (Makker et al. 2002). Pectin induces apoptosis in human prostate cancer cells (Jackson et al. 2007; Liu et al. 2008; Liu et al. 2010;1) According to the literature survey, the daily intake of pectin from fruit and vegetables can be estimated to be around $5 \mathrm{~g}$ (where the consumption of approximately $500 \mathrm{~g}$ fruit and vegetable per day is estimated). Pectin thus acts as a soluble dietary fibre. Consumption of pectin has been shown to reduce blood cholesterol levels. Intake of pectin increases the viscosity in the GI tract and allows reduced absorption of cholesterol from food. Micro organisms play an important role in degradation of pectin particularly in large instestine and colon and helps in liberating short chain fatty acids that produces beneficiary effects on the human health (Wakerly et.al 1996).

\section{Commercial Pectins:-}

Commercial pectins are produced mainly by acid extraction of apple pomace and citrus peel (BeMiller and Whistler, 1996). Commercial pectin is a by product of the fruit juice industry. Pectin is known to be a heat sensitive material, so temperature is monitored strictly during extraction in order to obtain the highest quality product possible (May, 1990). The raw material (pomace or peel) is dried after juice is extracted in order to prevent bacterial or mold growth. Enzymes produced by bacteria and mold are known to produce the enzymes pectin methylesterase and polygalacturonase. Fungal polygalacturonase cleaves the $\alpha-1,4$ bonds between D-galacturonic acid units, which degrades pectin quality and can have an adverse effect on the gelling ability of pectin. These enzymes may work within the pectin chain (endo-enzymes) or may remove polygalacturonic acid units from the ends of pectin chains (exo-enzymes). Fungal pectin methylesterase attacks the bond between methanol and carboxyl groups in pectin. The enzyme de-esterifies the polygalacturonic acid units in groups, which makes the resultant pectin much more sensitive to calcium despite the degree of esterification. Both types of enzyme degradation can take place over the course of a few hours. These enzymes are also extracted and produced commercially in order to obtain pectins with a specific molecular weight or degree of esterification (Willats et al. 2001). Pectins have a complementary bonding with dairy products and are able to make use of whey as a source of calcium, enhancing their innate capabilities for gelation, emulsification, and the ability to produce stable foams (Sriamornsak, 1998). Pedrolli et al. (2009) studied the characterization and pectin and its industrial application of microbial pectinolytic enzymes.

\section{Molecular Weight of Pectin:-}

Molecular weight of pectin is a key parameter to form a gel, the formation of gel is mostly affected by the molecular weight of the pectin it corresponds to the chain length due to the fact that the linear polymer chain must be long enough to accumulate a sufficient number of weak interactions to form stable cross-links (Rees, 1972). Neutral sugars, such as $\alpha$ - L-rhamnopyranosyl, are thought to be responsible for the chain irregularities that limit the size of the chains (BeMiller and Whistler, 1996). Chain length may also be affected by the presence of covalently linked side chains. The linked side chains give the molecule a "hairy" appearance.

The formation of gel is affected mostly by the molecular weight of pectin (BeMiller and Whistler, 1996). Pectin with a higher molecular weight considered to be of a better grade than pectin with a lower molecular weight. Processing of pectin limits the molecular weight of the finished product due to the depolymerization of pectin chains (Willats et al. 2001)Extreme acid or alkaline conditions can further reduce molecular weight of extracted pectin (Yapo et al., 2007). Alkaline conditions degrade pectin through a $\beta$-elimination reaction (May, 1990). Usually a higher molecular weight will yield stronger gel networks when compared to the low molecular weight (Pilgim et al. 1991).

\section{Degree of Esterification of Pectin:-}

Some of the carboxyl groups of pectin chains may be esterified with methanol. If the percentage of carboxyl groups esterified with methanol is over $50 \%$, the pectin is referred to as pectin with a high degree of esterification. When the percentage of carboxyl groups esterified with methanol is less than 50\%, the resultant pectin is said to have a low degree of esterification (Savary et al. 2003). As the number of carboxyl groups esterified with methanol approaches $100 \%$ (protopectin), pectin begins to lose its solubility in water and its ability to form a gel is lost (Bennion, 1980). Most pectins extracted from natural materials classified as having a high degree of esterification usually have less than 75\% of their carboxyl groups esterified (Pedersen, 1978). Pectins with a degree of esterification between 60 and 
$80 \%$ are highly soluble in water (Gee et al., 1958). Pectins can stop the milk protein in yoghurt from curdling with heat, so heat treated (UHT) long life yoghurt drinks can be made so pectin is added in yogurts.

When pectin is extracted from raw materials, the type of fruit, the degree of ripeness and extraction conditions all play a role in the degree of esterification that the extracted pectin will have. As fruit ripens and is converted from protopectin to pectin, the degree of esterification decreases (Gee et al., 1958). As pectin is extracted from raw material, an alkaline $\mathrm{pH}$ can de-esterify methyl groups and thus decrease the degree of esterification of the extracted pectin (Koch and Nevins, 1989). Extended heat processing seems to have a minimal effect on the degree of esterification (Postlmayr et al., 1956, Yapo et al., 2007).

\section{Mechanism of Gelation:-}

One important characteristic of pectin is its ability to form gels. Gelation is the association or cross-linking of long polymer chains to form a three dimensional continuous network, which traps and immobilizes liquid within to form a firm and rigid structure (Yeoh, 2008). The sol to gel transition occurs because randomly dispersed polymer segments associate in such a way that solvent is contained in its interstices. (Fig 1)

The characteristic differences between gels arise because of variations in network flexibility, the number and nature of cross-links, attraction and repulsions between network elements, and polymer-solvent interactions. The degree of esterification (DE) in pectin determines its solubility and gelling behavior. The ester group is less hydrophilic than the carboxyl group; so high ester pectin will gel at a faster rate and at a higher temperature than low methoxyl pectin. High methoxyl and low methoxylpectins gel under completely different conditions. High methoxyl pectin requires a minimum amount of sugar (usually more than 55\%) and a low $\mathrm{pH}$ (below 3) to form a gel whereas low methoxyl pectin requires bivalent cations like calcium in order to a form a gel (BeMiller and Whistler, 1996). It should be noted that in high methoxyl pectin gels, an excess of $70 \%$ soluble solids will cause pectin to fall out of solution and thus decrease gel strength (Molyneux et al., 1971). In low methoxyl pectin gels, gelation may also be affected by the hardness of the water used during processing, due to the presence of calcium in hard water. (Walkinshaw and Arnot 1981; Yalpani 1988)

The gelation process can be affected by many parameters. These include the degree of methylation, distribution of charge along the backbone, average molecular weight, ionic strength, $\mathrm{pH}$, temperature, and presence of soluble solids. The neutral sugar side chains, (such as $\alpha$-L-rhamnopyranosyl), can hinder gel formation. These side chains may be able to form weak bonds on their own, thus interfering with the pectin"s ability to form a gel network (Thakur et al., 1997). Extracted pectins with the same degree of esterification may show different sensitivities to calcium or different set rates. This difference may be attributed to the differences in fruit the pectin was extracted from (May, 1990).

Pectins are negatively charged molecules, the charge can interfere with gelation. As $\mathrm{pH}$ increases, the charge density increases, which can prevent pectin chains from forming junction zones (Thakur et al., 1997). An increase in $\mathrm{pH}$ can also cause splitting of glycosidic bonds within the pectin molecule, lowering the molecular weight of the molecule and decreasing its gelling ability (Albersheim et al., 1960). If the $\mathrm{pH}$ is well above the $\mathrm{pKa}$ value for the acid groups of the pectin chain, then the negative charge of the chain will likely prevent gelation (May, 1990). Enzymatic extraction of pectin from pumpkin was found to stable and good gelation properties (Shkodina et al. 1988).

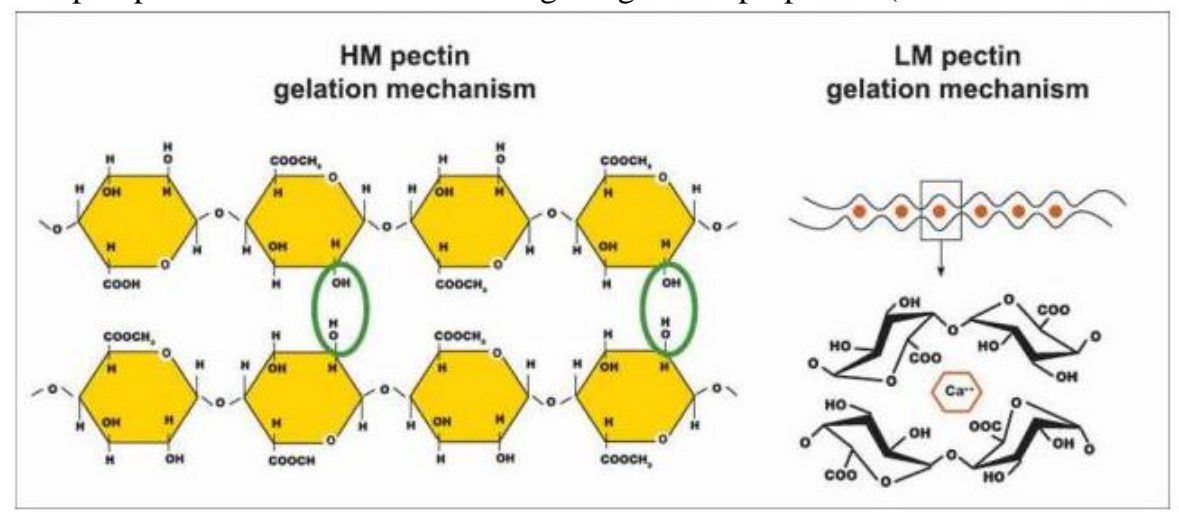

Fig 1:- Mechanism of Pectin gelation 


\section{Gels from Low Methoxyl Pectins:-}

The strength of low methoxyl gels is dependent on the pectin molecular weight, degree of polymerization, and calcium binding power. An increase in ionic strength and a neutral $\mathrm{pH}$ both decrease the amount of calcium needed to form a gel (Thakur et al., 1997). Low methoxyl gels may also be formed over a wider $\mathrm{pH}$ range than their high methoxyl counterparts ( $\mathrm{pH} 3-6)$, but as $\mathrm{pH}$ decreases the rate of gelation generally increases . Thus low acid pectin gels may require significantly longer setting time. The addition of sequestrants such as citrate or other fruit anions has a noticeable effect on low methoxyl gels and can be beneficial to gel strength. Care should be taken, however, when adding citric acid to a low methoxyl gel, since it may interfere with the complexing ability of divalent ions such as calcium (May, 1990).

Low methoxyl pectin forms gels through divalent ion, such as Ca++ or Mg++ (Bennion, 1980). Low methoxylpectins do not require sugar in order to form a gel network, and thus are used to produce and formulate reduced and no-sugar gels (BeMiller and Whistler, 1996). The relative abundance of free carboxyl groups found in low methoxyl pectin allows positively charged divalent cations to form "bridges" with the negatively charged free carboxyl groups. Calcium "bridges" are formed between two separate chains that are in thus eventually forming a three-dimensional network (Thakur et al., 1997). A section of backbone of the pectin molecule must be free of ester groups for calcium ions to be able to form this "bridge". The structure of the gel formed with divalent ions and pectin is known as egg box model (May, 1990). These "bridges" are formed by unbranched, non-esterified galacturonan blocks bound by calcium ions. By increasing the amount of calcium in a gel, the gel strength and gel temperature increase as well (BeMiller and Whistler, 1996).

The addition of excess amounts of calcium can have adverse effects on the pectin gel, however. At $\mathrm{pH} 3-5$, excess calcium can cause extensive cross-linking within the gel and syneresis may occur (Thakur et al., 1997). If the concentration of pectin is high in a low methoxyl gel, an addition of a small amount of calcium will yield an elastic gel. However, increasing the level of calcium when the pectin concentration is low will cause a brittle gel to be formed and in many cases syneresis will result (May, 1990). Low methoxyl pectin generally produces more brittle, inelastic gels than high methoxylpectins and thus mouth feel of the two gels are completely different. Due to the versatile properties of low methoxyl pectin, it can be used as not only as a gelling agent but also as a thickener (May, 1990).

The gel temperature of low methoxylpectins is dependent on several factors: percentage of soluble solids, calcium concentration, $\mathrm{pH}$, and pectin structure (Pedersen, 1978). Low methoxyl gels are also highly dependent on the degree of esterification, (between 30-50\%) and are not less affected by changes in molecular weight.

\section{Gels from High Methoxyl Pectins:-}

The formation of high methoxyl gels requires the presence of sugar and acid (Bennion, 1980). As acid is added, the highly charged and hydrated carboxyl groups are converted into uncharged, only slightly hydrated carboxylic acid groups. The loss of charge and hydration allows for the pectin molecule to associate with other chains and for junction zones to form. The formation of junction zones is aided by the addition of sugar, which competes for the water and thus lowers the solvation of the polymer chain, which promotes chain-chain interactions (BeMiller and Whistler, 1996). For this reason, properties of high methoxyl gels depend strongly on molecular weight of pectin due to the increase in hydrogen bonding as a result of increased chain length (Speiser and Eddy, 1946).

Junction zones in high methoxyl pectin gels are stabilized by the presence of hydrogen bonds and hydrophobic interactions between pectin chains (Thakur et al., 1997). Hydrophobic interactions within the gel are promoted by the unfavorable interactions between water and the methoxyl groups of the pectin chain. Consequently, the methoxyl groups have a tendency to associate with each other in order to reduce the contact area with water. By reducing the number of non-polar methoxyl groups that are in direct contact with the water, the conformational stability of the network is increased (Thakur et al., 1997). It is thought that pectin molecules form a random coile promoted by these interactions are controlled by the degree of hydrogen bonding and hydrophobic interactions (Palin and Gietmann 2012).

The amount and type of soluble solids used in the gel also contributes to the overall gel strength. The strength of hydrophobic interactions are affected by both amount and type of solute (soluble solids), and thus the temperature of gelation, gel strength and kinetics of the development of the gel structure are all affected by the type of soluble solid (sugar) used to produce a high methoxyl pectin gel (Thakur et al., 1997). High proportions of glucose or fructose in 
a gel are known to be detrimental to forming a high methoxyl pectin gel network. Large concentrations of glucose may lead to $\mathrm{pH}$ increases, thereby increasing gel setting temperature. Conversely, a large proportion of fructose in a gel can lower the gel setting temperature. A common solution in industry is using a mixture of glucose and fructose syrups to obtain desired the gel quality (May, 1990).

As mentioned, hydrogen bonding in high methoxyl gels contributes gel stability. Hydrogen bonding may occur between the oxygen atoms of carboxyl groups. Hydrogen bonds are very weak and are easily broken, but due to the sheer number of bonds that may occur in a gel network, they make contribute substantially to the thermodynamic stability of the gel (Thakur et al., 1997). With an increase in pectin concentration, the number of hydrogen bonds in a gel network will increase (Kjoniksen et al., 1995). The firmness of high methoxyl pectin gels is dependent on temperature of storage, $\mathrm{pH}$, pectin concentration, and the type of sugar used in the gel (Thakur et al., 1997). At $\mathrm{pH}$ values well above the pKa value for carboxyl groups, the pectin molecule has a sufficiently negative charge to prevent gelation. By reducing the $\mathrm{pH}$, gelation may occur but require initially a very high ( $\sim 80 \%$ soluble solids) sugar content. The required soluble solids level may be reduced by continuing to decrease the $\mathrm{pH}$. However, a minimum 55\% soluble solid is needed to prevent that high methoxyl pectin gels from beginning to lose gel strength. (May, 1990)

Setting temperature in conjunction with $\mathrm{pH}$ may also affect the quality of a high methoxyl pectin gel. When soluble solids content is constant in a gel, an increase in $\mathrm{pH}$ can cause a decrease in strength above a certain critical limit. As the $\mathrm{pH}$ increases, the setting temperature decreases. As $\mathrm{pH}$ decreases, the setting temperature of the gel increases. If the setting temperature increases to the boiling point, this can have an adverse effect on the gel structure. The action of the boil can cause shearing and disruption of the gel network and syneresis and an incomplete gel network are the common result (May, 1990). Temperature during storage of the gels is also very important, and can have a major impact on pectin molecule interactions and the time needed to form a gel (Silva and Rao, 1995).

\section{Conclusion:-}

Today, commercial pectin is used in different applications such as jams, jellies, yogurt, acid dairy drinks and confectionery. As a nature derived product with approved nutritional benefits, pectin is in high demand. It is widely used as a texturizer, stabilizer, and emulsifier in a variety of foods and other industries. In low calorie foods it is used as a fat and sugar in the food industry, where new applications are constantly being discovered, and increasingly in pharmaceutical, in food and cosmetics applications. Modern tools of science such as genetic engineering can be used to modify pectins in vivo which can be use as a carrier of controlled release application based delivery systems, especially ionotropic gelation and gel coating. These simple techniques, together with the safe toxicity profile, make pectin a promising excipient for food industry and pharmaceutical industry for future applications.

\section{References:-}

1. Green, A.C., Charcon, S., Madar, Z., and Schwartz, B. (2000). Apoptosis cascade proteins are regulated in vivo by high intracolonic butyrate concentration: correlation with colon cancer inhibition. Oncol. Res. 12, 83-95. doi: 10.3727/096504001108747558

2. BeMiller, J. N. and R. L. Whistler. Carbohydrates. Food Chemistry. O. R. Fennema. New York, Marcel Decker: 157-223. 1996

3. Bennion, M. The Science of Food. New York. 1980

4. Da Silva JA, Rao MA. Rheology of structure development in high-methoxyl pectin/sugar systems. Food technology (USA). 1995.

5. Gee M, McComb EA, McCready RM. A method for the characterization of pectic substances in some fruit and sugar- beet marcs. Journal of Food Science. 1958;23(1):72-5. doi: 10.1111/j.1365-2621.1958.tb17540.x

6. Jackson CL, Dreaden TM, Theobald LK, Tran NM, Beal TL, Eid M, Gao MY, Shirley RB, Stoffel MT, Kumar MV, Mohnen D. Pectin induces apoptosis in human prostate cancer cells: correlation of apoptotic function with pectin structure. Glycobiology. 2007; 17(8):805-19. doi: 10.1093/glycob/cwm054

7. Koch JL, Nevins DJ. Tomato fruit cell wall I. Use of purified tomato polygalacturonase and pectinmethylesterase to identify developmental changes in pectins. Plant physiology. 1989; 91(3):816-22. doi:http://dx.doi.org/10.1104/pp.91.3.816

8. Kjøniksen AL, Hiorth M, Nyström B. Association under shear flow in aqueous solutions of pectin. European Polymer Journal. 2005; 41(4):761-70. http://dx.doi.org/10.1016/j.eurpolymj.2004.11.006 
9. Liu HY, Huang ZL, Yang GH, Lu WQ, Yu NR. Inhibitory effect of modified citrus pectin on liver metastases in a mouse colon cancer model. World J Gastroenterol. 2008; 14(48):7386-91. doi:10.3748/wjg.14.7386

10. Liu L, Li YH, Niu YB, Sun Y, Guo ZJ, Li Q, Li C, Feng J, Cao SS, Mei QB. An apple oligogalactan prevents against inflammation and carcinogenesis by targeting LPS/TLR4/NF- $\kappa B$ pathway in a mouse model of colitisassociated colon cancer. Carcinogenesis. 2010 ;31(10):1822-32.doi: 10.1093/carcin/bgq070

11. May CD. Industrial pectins: sources, production and applications. Carbohydrate polymers. $1990 ; 12(1): 79-99$. doi:10.1016/0144-8617(90)90105-2

12. Willats WG, Orfila C, Limberg G, Buchholt HC, van Alebeek GJ, Voragen AG, Marcus SE, Christensen TM, Mikkelsen JD, Murray BS, Knox JP. Modulation of the Degree and Pattern of Methyl-esterification of Pectic Homogalacturonan in Plant Cell Walls implications for pectin methyl esterase action, matrix properties, and cell adhesion. Journal of Biological Chemistry. 2001; 276(22):19404-13. Doi:10.1074/jbcM011242200

13. Mohnen D. Pectin structure and biosynthesis. Current opinion in plant biology. 2008; 11(3):266-77. doi: 10.1016/j.pbi.2008.03.006

14. Molyneux, F. (1971). "Manufacture of Jams, Sauces and Pickles." Process Biochemistry: 17-78.

15. Nangia-Makker P, Hogan V, Honjo Y, Baccarini S, Tait L, Bresalier R, Raz A. Inhibition of human cancer cell growth and metastasis in nude mice by oral intake of modified citrus pectin. Journal of the National Cancer Institute. 2002 ;94(24):1854-62. doi: 10.1093/jnci/94.24.1854

16. Palin R, Geitmann A. The role of pectin in plant morphogenesis. Biosystems. 2012; 109(3):397-402. http://dx.doi.org/10.1016/j.biosystems.2012.04.006

17. Pedrolli DB, Monteiro AC, Gomes E, Carmona EC. Pectin and pectinases: production, characterization and industrial application of microbial pectinolytic enzymes. Open Biotechnology Journal. 2009; 9-18. http://dx.doi.org/10.2174/1874070700903010009

18. Pilgrim GW, Walter RH, Oakenfull DG. Jams, jellies, and preserves. The chemistry and technology of pectin. 1991:25-35.

19. Postlmayr HL, Luh BS, Leonard SJ. Characterization of pectin changes in freestone and clingstone peaches during ripening and processing. Food Technology. 1956; 10(12):618-25.

20. Rees, D. A. (1972). "Polysaccharide Gels - A Molecular View." Chemistry and Industry 19: 630-636.

21. Savary, B.J. A.T. Hotchkiss, M.L. Fishman, R.G. Cameron, R.G. Shatters, Development of a Valencia orange pectin methyl esterase for generating novel pectin products. F. Voragen, H. Schols, R. Visser (Eds.), Advances in pectin and pectinase research, Kluwer Academic Publishers, The Netherlands (2003), pp. 345-361

22. Shkodina OG, Zeltser OA, Selivanov NY, Ignatov VV. Enzymic extraction of pectin preparations from pumpkin. Food hydrocolloids. 1998; 12(3):313-6. http://dx.doi.org/10.1016/S0268-005X(98)00020-4

23. Sriamornsak P, Chemistry of Pectin and its pharmaceutical uses: A Review. J Pharm Pharmac Sce, 1998, 44: 207-228.

24. Thakur BR, Singh RK, Handa AK, Rao MA. Chemistry and uses of pectin - a review. Critical Reviews in Food Science \& Nutrition. 1997; 37(1):47-73. http://dx.doi.org/10.1080/10408399709527767

25. Wakerly Z, Fell JT, Attwood D, Parkins D. Pectin/ethylcellulose film coating formulations for colonic drug delivery. Pharmaceutical research. 1996 ;13(8):1210-2. doi:10.1023/A:1016016404404

26. Walkinshaw MD, Arnott S. Conformations and interactions of pectins: II. Models for junction zones in pectinic acid and calcium pectate gels. Journal of Molecular Biology. 1981; 153(4):1075-85. doi:10.1016/00222836(81)90468-X

27. Lionetti V, Cervone F, Bellincampi D. Methyl esterification of pectin plays a role during plant-pathogen interactions and affects plant resistance to diseases. Journal of plant physiology. $2012 ; 169(16): 1623-30$. http://dx.doi.org/10.1016/j.jplph.2012.05.006

28. Yalpani, M. Polysaccharides-synthesis, modification and structure/property relations. New York: Elsevier, 1988

29. Yamaki S, Machida Y, Kakiuchi N. Changes in cell wall polysaccharides and monosaccharides during development and ripening of Japanese pear fruit. Plant and Cell Physiology. 1979 ;20(2):311-21.

30. Yapo BM, Robert C, Etienne I, Wathelet B, Paquot M. Effect of extraction conditions on the yield, purity and surface properties of sugar beet pulp pectin extracts. Food chemistry. 2007 ;100(4):1356-64. http://dx.doi.org/10.1016/j.foodchem.2005.12.012

31. Yeoh S, Shi JT, Langrish TA. Comparisons between different techniques for water-based extraction of pectin from orange peels. Desalination. 2008; 218(1):229-37. doi:10.1016/j.desal.2007.02.018 